\title{
Clausal Backgrounding and Pronominal Reference: A Functionalist Approach to C-command
}

\author{
Catherine L. Harris \\ Elizabeth A. Bates \\ Boston University \\ University of California, San Diego
}

Address for Correspondence

- Catherine L. Harris

- Psychology Department

- Boston University

- 64 Cummington St.

- Boston, MA 02215

- USA

Email: charris@bu.edu 


\title{
Clausal Backgrounding and Pronominal Reference: A Functionalist Approach to C-command
}

\author{
Catherine L. Harris \\ Elizabeth A. Bates \\ Boston University \\ University of California, San Diego
}

\begin{abstract}
English speakers' intuitions are strong that pronouns as sentence subjects may not precede their

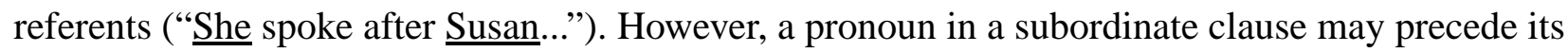

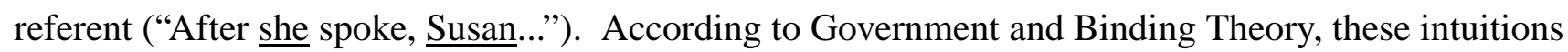
are subsumed by the principle of c-command, a phrase structure descriptor whose success at describing diverse grammatical phenomena has been widely interpreted as support for the autonomy of syntax hypothesis. We investigate an alternative view, that syntax signals (inter alia) foregrounding/ backgrounding structure. Listeners may consult this foregrounding/backgrounding information when inferring pronominal coreference. We backgrounded the main clause using progressive or pluperfect

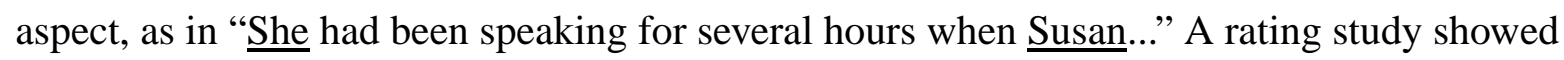
coreference was allowed more frequently for pronouns in main clauses when those clauses contained progressive or pluperfect aspect. A follow-up study showed that the constructional semantics of when subordinators contributes to backgrounding interpretations, as does semantic plausibility. Our experiments do not falsify c-command, but rather empirically develop the long-standing view that generalizations about syntactic structures (i.e., formal principles) can be motivated by correlations between form and function.
\end{abstract}


Harris and Bates

Page 3

\section{Clausal Backgrounding and Pronominal Reference: A Functionalist Approach to C-command}

Pronouns typically refer to the current topic of the discourse, which is often a just-mentioned noun phrase. For example, in John finished breakfast before he went to school, he refers back to John. This suggests that the function of pronouns is to facilitate rapid access to the current discourse topic (Ariel, 1990; Givon, 1983). The domain of pronominal reference might thus seem to be a prime example of how forms in language serve specific functions. However, pronominal reference is currently one of the success stories of autonomous syntax. This is the view that regularities in language must be studied in terms of abstract, formal rules that are independent of communicative functions (Chomsky, 1981; 1996; Lasnik, 1976;Newmeyer, 1998; Reinhart, 1981; Rizzi, 1997). Our goal in this paper is to dispute the usefulness of this view, but to provide foundation we begin with a brief review of how the domain of pronominal reference has come to be seen as a success story for autonomous syntax.

Early evidence against a functionally oriented approach to understanding pronominal reference was the observation that pronouns can sometimes, but not always, precede the nouns to which they refer. In the (a) examples in (1)-(3) the pronoun cannot be coreferent with the subsequent noun, but in the (b) examples it can.

(1) a. He finished breakfast before John went to school. (he $\neq$ John; from Carden \& Dieterich 1980)

b. After he finished breakfast, John went to school $($ he $=$ John)

(2) a. She stood up before Susan began to sing. (she $\neq$ Susan; from Gordon \& Hendrick 1997)

b. Before she began to sing, Susan stood up. (she = Susan)

(3) a. He ate the cake when the Smurf was in the box. (he $\neq$ the Smurf; from Crain, 1991)

b. When he was in the box, the Smurf ate the cake. (he $=$ the Smurf)

Examples (1)-(3) suggest that syntactic structure determines coreference patterns. In particular, it appears that pronouns may not precede their referents when the pronoun is the subject of the sentence, as in the (a) examples, but may when the pronoun appears in a syntactically subordinated clause, as in the (b) examples. This generalization has been extensively discussed by linguists (Langacker, 1969; 


\section{Functionalist Alternative to C-command}

Page 4

Lasnik, 1976; Reinhart, 1981, 1983; Ross, 1969; and others), and is supported by examination of written tests (Carden, 1982; van Hoek, 1997), and by psychological experiments (Gerken \& Bever, 1986; Gordon \& Hendrick, 1997; Smyth, 1986).

Since the 1960s linguists have sought to match patterns of prohibited and allowed coreference to distinct phrase structure configurations. The hierarchical structure of sentences has long been diagrammed such that branches of the phrase structure tree correspond to clauses. In such diagrams, pronouns generally can only refer to referents that are higher then they are in the phase structure diagram (Lasnik, 1976; Reinhart, 1981, 1983; Ross, 1969). The most widely accepted generalization is that a pronoun cannot be coreferent with a noun phrase that c-commands it. A node $y$ is c-commanded by a node $x$ if $y$ is at the same level in the tree as $x$ or is a descendant of any of the nodes at the same level as $x$ (Radford, 1988).

C-command has proved useful for describing grammatical phenomena beyond pronominal reference (Freidin, 1992). This descriptive success has been interpreted as support for the autonomy of syntax hypothesis. Psycholinguists have turned their attention to the problem of how this principle interacts with parsing and sentence comprehension (Nicol \& Swinney, 1989; Swinney \& Osterhout, 1988) and how children could learn such an abstract principle (Berwick \& Wexler, 1987; Crain, 1991; Goodluck, 1981; McKee, Nicol, \& McDaniel, 1993; Solan, 1981.) Crain (1991) found that children were sensitive to the distinction in sentences (3a) and (3b) as soon as they could understand sentences containing subordinate clauses. Rizzi (1997) notes that this "early manifestation in acquisition of the non-coreference principle" makes it a good candidate for being part of an innate system.

Many linguists have noted that height in the phrase structure tree appears to correspond to prominence or accessibility of information (Ariel, 1990). What remains controversial is whether descriptions of phrase structure relations such as c-command should be set aside in favor of descriptions cast in cognitive terms (Newmeyer, 1998). Our position is that c-command may correlate with grammaticality intuitions and with children's interpretations of pronouns, but this does not require that children (or adults) have knowledge of the c-command principle (Harris, 1991). Instead, both adults and children may be sensitive to the backgrounding properties of syntactic subordination. The 
when clause subordinator may be a cue that the information in this clause is background or context for understanding the upcoming clause, which is the main clause of the sentence (Bosch, 1983). Interpreting a pronoun as coreferent with a subsequent noun phrase is one strategy for integrating the two clauses.

Do sentences exist for which a backgrounding account of permitted coreference makes different predictions from c-command? Example (4) may be one such case, as coreference appears acceptable here. In this sentence, backgrounding of the initial clause is achieved with pluperfect aspect, not by syntactic subordination.

(4) He had been staring at the control panel for over an hour when Jack received a message from his commander. (from Lakoff, personal communication in August 1987)

Sentences like (4) indicate that backgrounding using aspect may license reference between a sentence-initial pronoun and subsequent proper name. We propose that it is the function of backgrounding which permits a pronoun to deviate from its normal role of referring backwards to an established discourse entity. On this view, c-command's descriptive success is a by-product of the functional properties of sentential structure.

\section{Functionalist Approaches to Pronominal Reference}

Functionalist grammarians argue that grammatical structure is motivated by the functions of language, particularly the function of communication (Bates, \& MacWhinney, 1982; Newmeyer, 1998). There is general agreement that the main function of pronouns is to refer to discourse entities that are highly accessible in working memory (Garnham, 1987; Givon, 1983; Gordon \& Hendrick, 1997; Prince, 1981). Language users appear to be sensitive to the accessibility status of a concept, and use a full noun if some amount of time has passed since the noun was last mentioned (Ariel, 1990; Givon, 1983). When a speaker encodes a concept as a pronoun, this is understood by hearers as a cue that the concept is highly accessible, indeed, is probably the current discourse topic. In contrast, encoding a concept as a noun phrase signals that the concept is less accessible. Lowered accessibility may be a matter of number of words since last mention, or may result if other noun phrases have been mentioned. 
In sentences like $\underline{H}$ e finished breakfast before $\underline{\text { John }}$ went to school, and the (a) examples in (1-3), the pronoun signals "highly accessible in working memory" for two reasons: because this is the function of pronouns, and also $\mathrm{He}$ in this sentence is encoded as sentence subject. Sentence subject is most frequently the position accorded to the current discourse topic (Langacker, 1987; Li, 1976; Givon, 1983). Encoding John as a proper name rather than as a pronoun signals that John is a new concept, and not highly accessible in working memory. This conflict in accessibility status leads to the intuitions that $H e$ and John cannot refer to the same entity.

If pronouns signal that the entity they encode already exists in working memory, why are pronouns allowed in some cases to refer ahead to a subsequent name, as in the (b) examples of (1-3)? Functionalist grammarians have long emphasized the backgrounding function of subordination. Drawing on crosslinguistic analyses, Matthiessen and Thompson (1988) note that subordinate clauses usually signal a condition, reason, purpose, cause, setting, manner, or means. The main clause is understood to be the main or focal assertion. Subordinate clauses thus function as context in which to interpret or evaluate the speaker's main assertion. In an analysis of information flow in narrative texts, Hopper (1979) observed that narrative backgrounding is frequently conveyed with syntactic subordination.

Phrase structure diagrams capture the lesser informational prominence of the subordinate clause by placing it under an S node which is at the same level of the NP and VP of the main clause. This means that a pronoun subject in the main clause c-commands all other nodes in the tree, while a pronoun subject in the subordinate clause does not. In Carden's (1982) study of pronouns which precede their referents, nearly all cases were of this type.

Numerous researchers have noticed the correspondence between a pronoun in a subordinate clause and the ability of that pronoun to refer ahead to a subsequent noun phrase. Chafe (1984) notes that when the subordinate clause is placed before the main clause, the clause linkage is anticipatory: the first clause must be followed by a second clause, barring a change of mind on the part of the speaker. Because subordinate clauses provide a context in which to evaluate or interpret a main point, listeners will attempt, where possible, to integrate material across clauses, or to seek reasons why material in the 
first is relevant to the second. An interpretation of coreference between nouns in different clauses is one way to integrate them.

Placing a pronoun in a subordinate clause (syntactic subordination) therefore allows it to refer ahead to its referents (Bolinger, 1979; Kuno 1987; van Hoek, 1997). One purpose for opening a sentence or paragraph with a subordinate clause is to build suspense or lay groundwork (Smyth, 1986). The speaker may prefer to use a pronoun in the background material, allowing the full name of the character to be encoded as the sentence subject. Sentence subject position accords it informational prominence, meaning that listeners will dedicate processing resources to establishing that noun phrase as the sentence topic and will expect it to continue to be important in the discourse.

Examples (5) and (6) illustrate the greater naturalness of reserving sentence subject as the place for introducing a new discourse topic, especially a multi-word name (van Hoek, 1997).

(5) a. Before they were gunned down, the Gibraltar Three were planning to blow up a band... (The Nation, October 1989; cited in van Hoek, 1997).

b. Before the Gibraltar Three were gunned down, they were planning to blow up a band...

(6) a. While he hadn't read the Gifford article, Associate Dean of Yale College Martin Griffin said that the 'best administrators are scholars', and that... (Yale Daily News, Jan.78).

b. While Associate Dean of Yale College Martin Griffin hadn't read the Gifford article, he said that the 'best administrators are scholars', and that...

Thus far, functionalist accounts make the same prohibited vs. free predictions as does c-command. The difference between the two accounts is the causal arrow. In the generative tradition, coreference patterns are caused by constraints between the nodes in a phrase-structure tree. From the functionalist perspective, coreference patterns are caused by communicative constraints. Phrase structure trees are then drawn in a manner that uses height in the tree to notate relative informational prominence.

If the backgrounding function, and not syntactic subordination per se, allows pronouns to precede their referents, a test case would be a sentence type where c-command predicts blocked coreference, but where backgrounding is achieved by different means than syntactic subordination. The next section examines the case where clausal backgrounding is achieved via imperfective (progressive or pluperfect) aspect. 


\section{The Simple Past Versus Progressive Aspect}

Carden (1982) found example 7 in naturally-occurring text, and noted that c-command predicts that coreference is unacceptable here.

(7) She was sitting with 8,000 people in Madison Square Garden at a New York Apples match, when Phyllis Rothstein of New Rochelle...

The first clause uses past progressive aspect to describe a temporally extended event. This event is naturally construed as the setting for the punctate event that follows in the when clause.

When narrating a story, speakers typically convey both a story line (a sequence of events which are directed towards a point or climax), and also a set of comments or amplifications of the story line. Hopper (1982) has emphasized that, crosslinguistically, the most frequent device for signaling foreground and background is verbal aspect. Completive aspect (the simple past tense in English) is used to mark the sequential flow of events that typifies narrative foreground. Imperfective aspect (or progressive aspect), because it describes an event enduring over time, often signals narrative background (as in 7). Similarly, the pluperfect marker had often signals background material because it also refers to material that is outside a single sequential time-line, as in (8a) below.

Examples of exceptions to c-command appear in (8) (from Bolinger, 1979). In all three the pronouns appear in a clause with imperfect aspect.

(8) a. He had already shot himself before John quite knew what he was doing.

b. He would have been like a son to both us, if my wife and I could have kept Jim away from the influence of his family.

c. He was just a little boy when I knew John.

Many of the sentences with initial clauses backgrounded via aspect (in 4,7 and 8) use when as the subordinating clause). Is there something special about when clauses? Intuitive readings suggest that conjunctives such as after, before and while do not as easily allow coreference as does the when subordinating conjunction. When may itself be a backgrounding clue, and may also have constructional semantics that, together with aspect, license a backgrounding interpretation for the first clause. These ideas are explored in Experiment 4. 
Our primary hypothesis is that coreference is possible in sentences like those in examples 4, 7 and 8 for the same reason that it is possible when pronouns appear in a subordinate clause: because the initial clause serves a backgrounding function. Hence manipulating aspect of the main clause provides a critical test between functionalist explanations and a purely syntactic account of when pronouns can precede their referents. ${ }^{1}$

\section{Experiment 1: Coreference judgments to isolated sentences}

This experiment compared raters' coreference preferences for three types of sentences, presented in Table 1. If c-command restricts coreference possibilities, then raters should disallow coreference between the pronoun and noun phrase for both of the main-clause conditions, regardless of aspectual backgrounding. But if the operative factor is the foreground-background structure of the sentence, then raters should be more accepting of coreference for sentences with progressive aspect. The subordinate condition was included to directly compare backgrounding via aspect to backgrounding via syntactic subordination.

\section{Method}

\section{Design and Materials}

We created 45 target sentences such that three versions of each sentence could be written to fit the three conditions described in Table 1. The aspect manipulation was either past progressive ("He was threatening to leave..."), or pluperfect ("He had just begun unpacking"). For convenience these will be referred to jointly as progressive aspect. The adverb when was always used in the progressive aspect

1. It could be argued the sentences we have cited are not exceptions to c-command because the two clauses should be analyzed as co-ordinating structures, not a main-clause followed by a subordinate clause. This suggestion detracts from the definition and generalizability of c-command itself, by rendering it circular: if a sentence appears to violate c-command but elicits high acceptability ratings from native speakers, this is an indication that the two clauses are adjoining rather than a matrix-subordinate structure. The failure of standard theories is that they don't specify why sentence (4) is given a different structure from the matrix-subordinate sentences in examples (1)-(3). 


\section{TABLE 1: Stimulus Conditions for Experiment 1}

\begin{tabular}{|c|c|}
\hline & \\
\hline Initial Clause Type & Example \\
\hline
\end{tabular}

$\begin{array}{llll}\text { main, simple past tense } & \begin{array}{l}\text { He } \text { threatened to leave when } \underline{B i l l y} \\ \text { noticed that the computer had died. }\end{array} & \text { Blocked } & \text { Dispreferred } \\ \text { subordinate } & \begin{array}{l}\text { When he threatened to leave, } \underline{\text { Billy }} \\ \text { noticed that the computer had died. }\end{array} & \text { Allowed } & \text { Allowed } \\ \text { main, progressive aspect } & \begin{array}{l}\underline{\text { He }} \text { was threatening to leave when } \underline{B} \text { illy } \\ \text { noticed that the computer had died. }\end{array} & \text { Blocked } & \text { Allowed }\end{array}$

condition, but different adverbs were sometimes used in the other two conditions. Twenty-seven of the passages used as, just as, because, until, after, while or even though for the main and subordination conditions (see Appendix A for examples). Seventeen filler passages were constructed to display diversity in content, style and use of syntactic structures. Three stimulus lists (12 raters per list) were constructed so that raters saw only one version of each sentence, and saw equal numbers of sentences in each of the three conditions.

\section{Raters and Procedure}

Raters were 36 students from the University of California, San Diego, who participated for course credit. Each sentence on the paper-and-pencil questionnaire was followed by a question as to who performed the activity in the first clause. Choices were laid out as in the example below; raters were told that the "Either" option meant that either the named character or "Someone Else" could have performed the activity.

He was staying with some underground writers when Ben was asked to leave the country.

Who was staying with some underground writers?
Ben
Either
Someone Else
Ungrammatical

Raters were told to pick the response that best answered the question about who performed the 


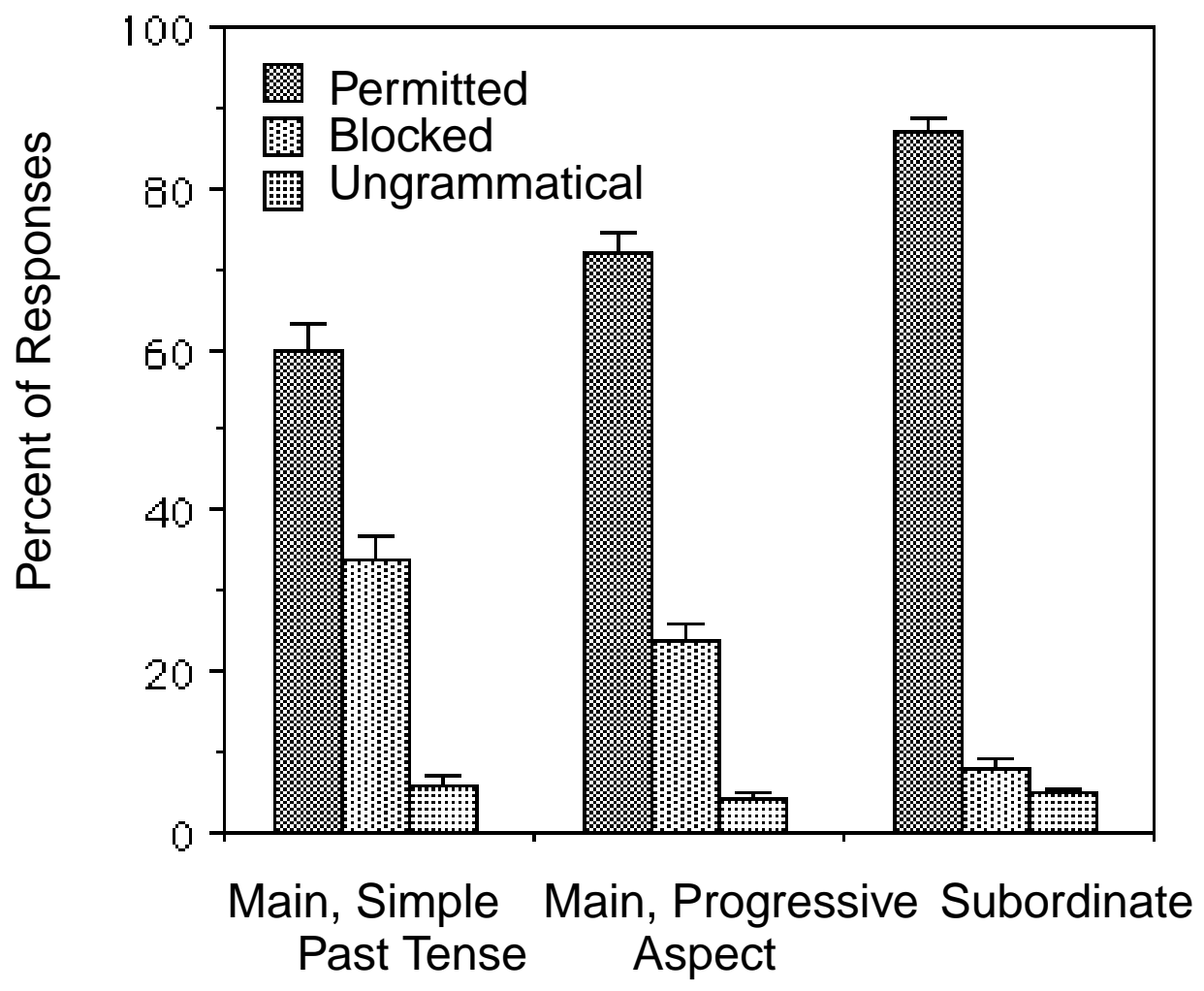

Figure 1. "Permitted coreference" refers to choices of the named character or the EITHER response; "Blocked coreference" means that raters chose the "Someone else" response. "Main, progressive aspect" refers to the sentence type with the pronoun in the main clause, with progressive or pluperfect aspect. Error bars indicate one standard error of the mean. 
activity. They were told that not all English speakers would agree on this and that there were no right or wrong answers. They were instructed to choose the "Ungrammatical" option if they felt the passage was "ungrammatical, semantically incoherent, or so oddly worded that it does not reflect the usage conventions of English.” Each sentence and response options were separated from the previous sentence with white space and ruled lines.

\section{Results and Discussion}

Selection of the "Either" response and choice of the named character as the referent of the pronoun were both scored as "permitted coreference." Choice of "Someone else" was labeled "blocked coreference." Figure 1 shows that the pattern of responses for sentences with progressive aspect is midway between the other two conditions, as verified by a within-item one-way analysis of variance. Permitted coreference judgments were higher for the progressive aspect than the simple past tense condition, $F(1,44)=8.6 ; p<.01$, but lower than for the subordinate condition, $F(1,44)=12.1, p<.001$.

\section{Place Figure 1 Here}

The prediction of more acceptance of coreference when a main clause had progressive aspect was supported. Raters more frequently permitted coreference in the subordinate clause condition than in the progressive aspect condition. This suggests that progressive aspect is a weaker method of backgrounding than syntactic subordination.

Before further investigation of issues related to aspect and pronominal reference, it would be helpful to directly link the aspect manipulation to backgrounding in the sentences used in this experiment. Otherwise, we are restricted to relying on prior arguments about the narrative function of aspect (Hopper, 1982) and linguistic intuitions about the meaning of our sentences. This question was addressed in Experiment 2, where we inferred degree of backgrounding using a story-continuation method (Gernsbacher \& Shroyer, 1990). 


\section{Experiment 2: Measuring Backgrounding}

It is uncontroversial that speakers use the subject position of a main clause to encode the topic or main idea ( $\mathrm{Li}, 1976)$. Theorists also concur that subordinate clauses are used to encode supporting or background information (Matthiessen \& Thompson, 1988). However, there is relatively little work linking level of grammatical encoding to how accessible or informationally prominent a concept is. Even less is known about the informational prominence of subjects in the sentence types studied in the current paper, namely, subjects of main clauses which have progressive or anterior aspect.

In Experiment 2 we displayed single sentences on a computer screen, using sentences with two named characters, such as those in (9).

(9) a. main clause, simple past tense: Frank rubbed his tired eyes in fatigue when Jack spotted the car behind a billboard.

b. main clause, progressive aspect: Frank was rubbing his tired eyes in fatigue when Jack spotted the car behind a billboard.

c. subordinate clause: While Frank rubbed his tired eyes in fatigue, Jack spotted the car behind a billboard.

Research participants were asked to orally produce a continuation sentence. Following Gernsbacher and Shroyer (1990), we assumed that informationally prominent characters would be more likely to be mentioned in the continuation sentence (or mentioned first). The most prominent character in the subordinate clause condition in (9c) should be Jack, because Jack is the sentence subject. Jack should be mentioned less frequently in the main clause, simple past tense condition, because here Jack is in the subordinate clause. If the pattern of mention in the progressive aspect condition is similar to the subordinate clause condition, then we can infer that progressive aspect is achieving a similar backgrounding function to syntactic subordination.

\section{Method}

\section{Materials}

Eighteen of the sentences in Experiment 1 were modified so that the sentence-initial pronoun was replaced with the name of a person, as illustrated previously in (9). Three stimulus lists were created so 
that each research participant saw only one version of each sentence, and saw six instances of each of the three conditions (all sentences appear in Appendix B). Six filler sentences contained only one name and did not use a main-subordinate clause format, to reduce the appearance of sameness of materials.

\section{Participants and Procedure}

Forty undergraduates at Boston University participated to receive course credit. The following instructions were read aloud at the start of the experiment.

You will see a sentence on the screen. Pretend that the sentence is part of a larger passage. It could be a news report or a piece of fiction, or could be a sentence from a spoken, informal conversation. Your job is to think of what the next sentence in the passage is likely to be. Simply speak out loud and tell the experimenter what the possible next sentence is.

The experimenter immediately wrote down the continuating sentence, and also pressed computer keys corresponding to which of the two characters was spoken first, whether the characters were referred to jointly (such as "they" or "the boys") or whether no character was mentioned. The experimenter was a research assistant who was uninformed about the research hypothesis.

\section{Results and Discussion}

We predicted that information in main clauses would be more prominently mentioned than information in subordinate clauses. When sentences begin with a subordinate clause (what we have called the subordinate clause condition), the second character's name is in the main clause. As predicted, in this condition, the second character was most frequently given first mention, followed by the progressive aspect condition, with least mention in the main clause, simple past tense condition (see Table2). The progressive aspect condition was significantly different from the main clause condition, $\mathrm{F}(1,39)=6.7, \mathrm{p}<.02$, and from the subordinate clause condition, $\mathrm{F}(1,39)=5.1, \mathrm{p}<.05$. For comparison purposes, we measured two other aspects of participants' continuations. Frequency of mention of the first name differed in the expected direction across the conditions, but the effect was extremely weak, and not statistically significant. Mention of the first name may have been less influenced by the our clause-type manipulation given that the fact of being the first name is itself a cue to prominence (the 
Table 2: Percentage of Trials when First or Second Name Mentioned First, Experiment 2

\begin{tabular}{|c|c|c|c|c|}
\hline Clause Type & $\begin{array}{l}\text { Second } \\
\text { Name }\end{array}$ & $\begin{array}{l}\text { First } \\
\text { Name }\end{array}$ & They & Example of Sentences \\
\hline Main, simple & 25 & 40 & 25 & $\underline{\text { Frank }}$ rubbed his tired eyes.....when $\underline{\text { Jack... }}$ \\
\hline Main, progressive & 35 & 36 & 20 & $\underline{\text { Frank }}$ was rubbing his tired... when $\underline{\text { Jack... }}$ \\
\hline Subordinate & 46 & 32 & 12 & While Frank rubbed his tired eyes... Jack... \\
\hline
\end{tabular}

Table Note. 'Second and first name percentages reflect trials on which the second or first name was mentioned first in the continuation sentence. "They" indicate trials on which participants avoided names and referred to both characters using they or "the two."

"Advantage of first mention" principle discussed by Gernsbacher, 1990). We also measured the percentage of trials in which participants avoided names and referred to both characters as "they" or "the two." With this measure, main and subordinate clauses differed from each other, $F(1,39)=4.9, p<$ .05 , but the aspect condition did not differ from the simple past tense, $F(1,39)=1.5, p>.20$.

The finding that mention of the second character for the progressive aspect condition was midway between the other two conditions supports the contention that progressive aspect in the first clause raises the prominence of information in the second clause, although not as strongly as does syntactic subordination of the first clause.

Data from the sentence-continuation experiment supports the hypothesis that progressive aspect serves a backgrounding function, albeit less strongly than does syntactic subordination. Names in the second clause of our sentences were more prominent in readers' discourse model in the subordinate clause and progressive aspect conditions, compared to the main clause, simple past tense sentences. Note that this experiment is the first to measure backgrounding and foregrounding using the "generate next plausible sentence" technique. Now that we have verified that progressive aspect does serve a backgrounding function, we will continue, in the remaining experiments, to investigate pronominal reference in these and comparison sentences.

\section{Experiment 3: Coreference Judgments In Context}

A question about the data in Experiment 1 is why raters allowed coreference as frequently as they 


\section{Functionalist Alternative to C-command}

Page 16

did. Even with no backgrounding cues of any kind, raters permitted coreference $60 \%$ of the time (i.e, in the main clause condition; see Figure 1). Yet this is the condition for which all theorists agree that coreference is dispreferred. One proposal is that coreference is so high in our data because raters were presented with isolated sentences. Language comprehenders may seek to "minimize discourse entities" (Prince, 1987). That is, raters may find it easier to relax their dispreference for coreference in these "blocked" sentences than to conjure up a hypothetical second actor who was left out of the sentence.

A straightforward method of testing this is to provide raters with an explicitly mentioned extrasentential referent, as done in (10). Providing raters with two candidate referents, one inside the sentence and one outside the sentence is a method followed by several past researchers (Carden \& Dieterich, 1980; Smyth, 1986; Solan, 1981).

(10) Ben and Dave were excited about being in Moscow. Dave wanted to meet some Russian dissidents. He stayed with some underground writers when

a. Ben was ordered to leave the country.

b. Dave was ordered to leave the country.

The comparison between examples (10a) and (10b) illustrates the "repeated name/new name" factor. This allowed us to investigate whether backgrounding via aspect is similar to syntactic subordination in how readily reidentification (renaming) is tolerated. Repeating a name after it has been pronominalized is frequently unacceptable, particularly when the pronoun is the subject of the sentence, as in (10b) (Gordon et al., 1993; Brennan, 1995). Bolinger (1979) and Ariel (1990) note that renaming of the referent is well tolerated when the pronoun appears in a subordinate clause. An example of this in our materials appears in (11).

(11) Ben and Dave were excited about being in Moscow. Dave wanted to meet some Russian dissidents. When he stayed with some underground writers, Dave was ordered to leave the country.

The repeated name condition can be seen as a conflict situation. Because pronouns usually refer backwards to established discourse topics, readers are likely to link the pronoun to the character who was topicalized in the previous sentence. A conflict may then occur when the discourse topic is renamed. Does backgrounding via aspect reduce this conflict, as measure by increased acceptance of 
coreference in this condition compared to the main clause, simple past tense condition?

New passages were constructed so that all conditions used when subordinate clauses. The subordinating when conjunction may have a constructional semantics which facilitates a backgrounding reading. Furthermore, examples such as (12a-b) suggest that there are two when constructions (Ritchie, 1979; Moens \& Steedman, 1988). In (12a), Bill's divorce threat precedes Sue's kick and is the setting or background for the kick. In (12b) the divorce threat comes immediately after her kick, and is likely to be the result of the kick.

(12) a. Bill was threatening to divorce Sue when she kicked him. [setting, event] b. Bill threatened to divorce Sue when she kicked him. [result, cause]

Examining many such pairs suggests that aspect influences interpretation in a predictable way. If clause 1 is progressive, then the sentence has the setting-event interpretation illustrated by (12a). If clause 1 describes a punctate (non-durative) event, then the sentence has the result-cause meaning illustrated by (12b).

In Hopper's (1979) and Matthiessen and Thompson's (1988) analyses of cross-linguistic texts, settings and causes are interpreted as background material, while events and results encode foreground material. The foreground-background structure of when constructions appears to be flexible (Moens \& Steedman, 1988). Clause 1 is interpreted as a setting (background) if it has progressive aspect, but is interpreted as the result of an action (cause) if it has simple past tense. By constructing all our passages using when as the subordinator, only presence or absence of progressive aspect is used to induce a backgrounding interpretation.

\section{Method}

\section{Design and Materials}

The design of Experiment 3 differed from Experiment 1 in that the three conditions of main clause, subordinate clause and progressive aspect were recast into 4 sentence types defined by the $2 \mathrm{X} 2$ design of main vs. subordinate and simple past tense vs. aspect. When crossed with the new name/ repeated name context conditions, a $2 \times 2 \times 2$ design resulted. 
Each rater received a questionnaire with 36 passages that were part of the 2 X 2 X 2 design. We also varied the order in which the two characters were introduced, although we did not expect this factor to influence judgments. Since it did not, we will not refer to it further. A computer program was written to rotate all passages through all conditions. This ensured that no participant saw more than one version of a passage, and that participants saw approximately equal numbers of passages (either 4 or 5) in each condition.

Filler passages were needed to increase diversity. Context was created for thirty sentences selected from those compiled by Smyth (1986, Experiment 1). These are sentences whose relevance for theories of pronominal reference was debated by linguists in the 1970's and 1980's and thus they exemplify a range of cases in which pronominal reference is not obvious.

\section{Raters and Procedure}

Seventy-eight raters (Boston University undergraduates who participated for course credit) completed paper-and-pencil questionnaires which they filled out individually while sitting in a laboratory room.

Instructions were modified from the Experiment 1 rating study as follows. The Either choice was removed, and the proper name choices were prefaced with Most Likely. A third choice was Someone Else. We also separated the Ungrammatical/odd category into two choices, "Ungrammatical" and "Odd". Raters could check off either or both of these, but were instructed to still answer the question about who performed the action by choosing a named character or by choosing the Someone Else option.

\section{Results and Discussion}

As in previous experiments, and as predicted by all theories of pronominal reference, coreference acceptances were substantially higher for subordinate clauses (75\% of trials) than for the main clauses (41\%). As shown in Figure 2, coreference is accepted less frequently in the main clause, progressive aspect conditions than in the subordinate clause conditions. This indicates that progressive aspect is a weaker backgrounding device than syntactic subordination, confirming the similar finding in 
Harris and Bates

Page 19

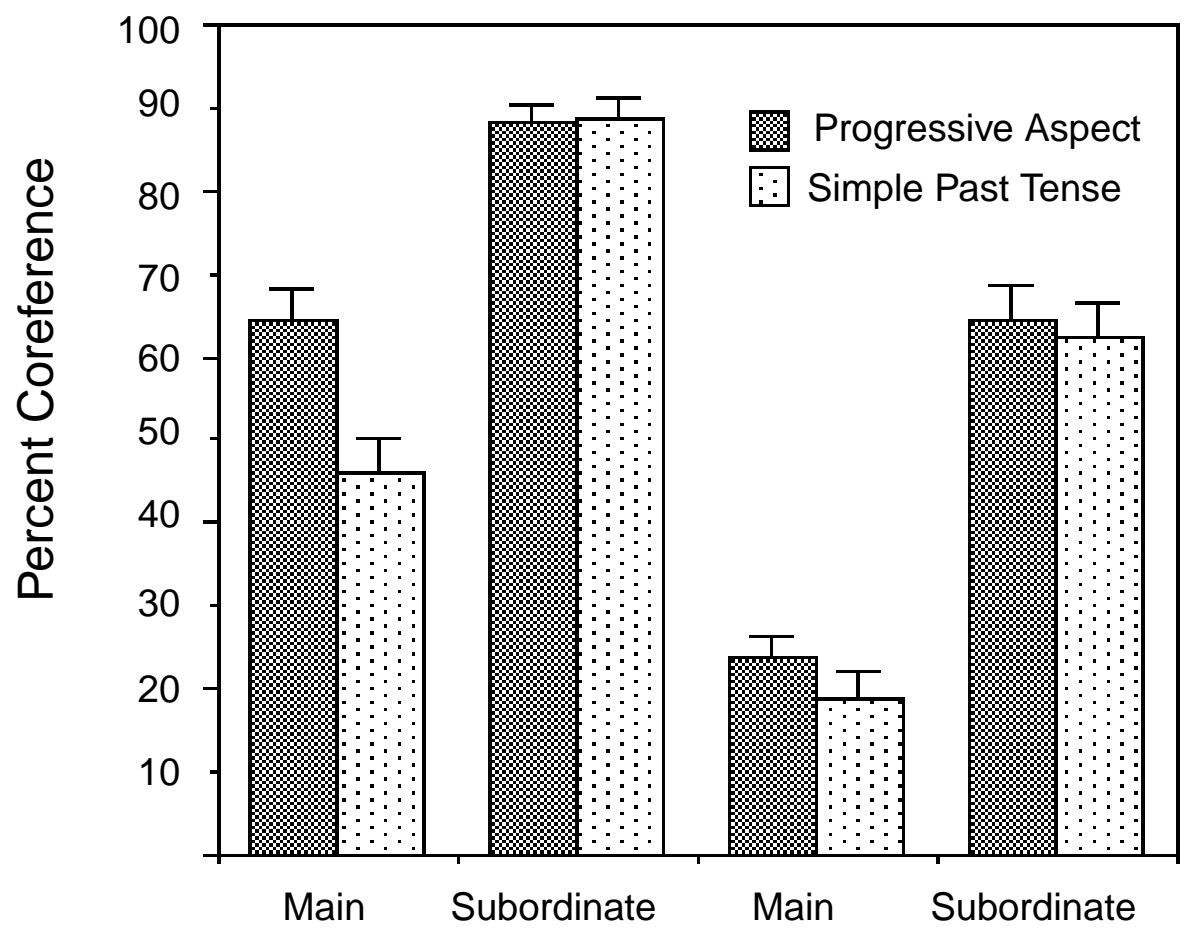

Repeated Name

New Name

Figure 2. Percentage of intrasentential coreference judgments in Experiment 3. Error bars correspond to one standard error of the mean. Percentages were calculated after excluding from each rater's data individual items judged to be "odd or ungrammatical" by that rater. 


\section{Functionalist Alternative to C-command}

Page 20

Experiment 1, which used single sentences rather than short passages. Note that progressive aspect did not influence coreference ratings when syntactic subordination was also present. We can infer that syntactic subordination is already such a strong and robust cue to backgrounding that aspect does not change the informational prominence of the clauses.

The test case involved main clause sentences with progressive aspect. As shown in Figure 2, progressive aspect increased acceptance of coreference in both the repeated name condition and the new name condition, with this effect being stronger in the repeated name condition. Statistical significance of the three-way interaction was verified in two ways. Items rated either odd or ungrammatical were excluded on a per-item, per-rater basis, yielding $\mathrm{F}_{1}(1,62)^{2}=7.6, p<.01$; $\mathrm{F}_{2}(1,35)=4.7, p<.05$. The three-way interaction was also significant after reclassifying judgments of odd or ungrammatical as prohibited coreference (regardless of how the rater had judged the item); $\mathrm{F}_{1}(1,77)=5.1, p<.03 ; \mathrm{F}_{2}(1,35)=7.0, p<.01$. The three-way interaction indicates that the difference between progressive aspect and simple past tense is smaller in the main clause, new name condition than in the main clause, repeated name condition. This was additionally verified through a planned comparison between the simple past tense and progressive aspect conditions (first two bars in Figure 2): $\mathrm{F} 1(1,77)=8.5, \mathrm{p}<.005 ; \mathrm{F} 2(1,35)=14.6, \mathrm{p}<.001$.

The new name condition presents no conflict to readers. Readers can simply choose the extrasentential referent, thus accommodating the standard function of pronouns which is to refer back to an established discourse topic. Only the repeated name condition presents a conflict to readers. Reidentification is awkward because a pronoun was just immediately used and the implication is then that this concept is highly available in the discourse representation (Ariel, 1990). The finding of more acceptance of coreference with backgrounding via progressive aspect suggests that adopting a backgrounding interpretation is a method of resolving this conflict.

Another important comparison in the repeated name condition involved holding aspect constant,

2. Analysis was conducted on only 63 subjects because 15 subjects had too much missing data after exclusion of judgments of "odd" and "ungrammatical". 
and comparison main clause to subordinate clause (first and third bars of Figure 2). This was also significant, $\mathrm{F} 1(1,77)=74.9, \mathrm{p}<.001 ; \mathrm{F} 2(1,35)=75.0, \mathrm{p}<.001$. This indicates that progressive aspect in a main clause does not facilitate coreference as strongly as does syntactic subordination.

\section{Place Figure 2 Here}

\section{Experiment 4: Semantic Plausibility and the When Construction}

The coreference judgments in Experiments 1 and 3 confirmed linguistic intuitions and previous empirical findings that raters more strongly prefer a referent outside the sentence for pronouns which are the subject of the sentence ("He stayed..."), compared to pronouns in a subordinate clause ("When he stayed...”). What remains puzzling is why this preference was not even stronger than it was. In Experiment 3,20\% of raters permitted coreference even in the new name condition, i.e, even when a different name had been topicalized in the prior sentence.

The $20 \%$ intrasentential preference rate is more than twice as high as the amount found by Gordon and Hendrick (1997). These authors used before and if constructions, and also prepositional adjuncts. In isolation, these yielded the low rates of coreference shown after each example in (13).

(13) a. She stood up before Susan began to sing. $6 \%$

b. He will pass the course if Bill does well on the exam. $2 \%$

c. She got a new car for Mary's birthday. $2 \%$

d. He keeps fresh herbs in Sam's kitchen. $\quad 4 \%$

These appear to be prototypical examples of blocked coreference. Reasons for the difference between our finding of $20 \%$ intrasentential coreference compared to these very low intrasentential ratings could be either the fact that we used when constructions, or differences in instructions. Our instructions (i.e., asking raters who did the action) focused on semantics rather than form. Gordon and Hendrick (1997; hereafter G\&H) focused explicitly on form: "[J]udge whether it was possible for two expressions to refer to the same person?" (p. 336). To help raters understand their task, G\&H also 


\section{Functionalist Alternative to C-command}

Page 22

provided example sentences, similar to those in the actual rating task, which were labeled as allowing or not allowing coreference.

We conducted a pilot study using passages built around the examples in (13) to determine if the low coreference rates found by G\&H would still be obtained using our instructions. Results revealed coreference patterns to be similar to those in G\&H (indeed, for the sentence in 13a, none of the 49 raters chose the referent inside the sentence). This shows that our instructions, which emphasize semantics, are nevertheless capable of identifying sentences in which a referent from outside the sentence is the universally preferred choice.

This suggests that our finding of $20 \%$ acceptance of coreference for sentences "blocked" by ccommand should probably not be attributed to semantic bias in our instructions. This makes it more likely that even without progressive aspect, the when construction itself facilitates a backgrounding interpretation of the first clause. This was investigated in Experiment 4 by comparing sentences using when subordinating conjunctions to those using after.

An additional factor varied was semantic plausibility. It is uncontroversial that semantic and pragmatic factors influence selection of referents for pronouns in addition to syntactic factors. Languages differ in how much they rely on syntactic factors. Huang (1994) has argued that pronominal reference in Chinese is almost entirely constrained by semantics and pragmatics. For a language that uses both syntactic and semantic/pragmatic factors, like English, one important question is whether semantic information is consulted independently of syntax, or whether semantic information interacts with syntax. In our final experiment we examine how choice of adverb (when vs. after) and progressive aspect interact with semantic plausibility.

As in the previous experiments, the two clauses were constructed so that it was logically possible for either the same or different person to be performing the actions in the two clauses. In example (14), it may be more plausible for William to be the person who is working quickly since he noticed that the wound was horribly infected.

(14) Leonard remarked that the patient looked bad. $\underline{\text { He }}$ worked quickly to find the right 
equipment when William noticed the wound was horribly infected.

Noticing is a private mental event and thus can only have a causal effect on the agent who does the noticing. In Experiment 3, about $60 \%$ of our passages used verbs that were private mental events; this could have biased raters towards intrasentential coreference. Preference for the extrasentential reference for passages such as (14) may result from raters' inference that William communicated the state of the wound to Leonard, which caused him to work quickly. Replacing mental state verbs like "noticed" with verbs of communication like "complained," as in (15), may thus increase choices of the extrasentential referent.

(15) Leonard remarked that the patient looked bad. $\underline{\mathrm{He}}$ worked quickly to find the right equipment when William complained the wound was horribly infected.

The semantic plausibility manipulation in the current experiment consisted of changing one word in each passage, corresponding to whether the verb of the final clause described a mental state or a verbal communication. The special semantics of the when construction, as opposed to other adverbial constructions, may interact with the mental state/communicator manipulation. The reason is that one of the meanings of when involves a cause-effect interpretation (Moens \& Steedman, 1988). Other clause-connectors, such as after, do not have this same cause-effect constructional semantics.

By using a mental state verb in a when construction, we are thus pitting against each other opposing forces: the semantics of the when construction and the default convention that when a pronoun is the sentence-initial subject ("He worked quickly...") it refers outside the sentence to the previously established discourse topic. Our hypothesis is that raters will strongly prefer extrasentential reference when a communicator verb is used, but that there will be some tendency for the referent inside the sentence to be selected when a mental state verb is used.

The constructional semantics of after are simpler than those of when. After specifies two sequential events which need have no relationship other than temporal succession, as in (16). Because no cause-effect relationship is required, we predict low acceptance of coreference, and no influence of the noticed/complained verb.

(16) Leonard remarked that the patient looked bad. He worked quickly to find the right 
equipment after William noticed/complained the wound was horribly infected.

\author{
Method
}

\title{
Design and Materials
}

Eighteen passages were adapted from those in Experiment 3 such that 6 versions could be written for each passage, thus implementing a $3 \times 2$ within-item, within-subject design. The 3-levels of the sentence-construction factor were the after adverb with simple past tense, the when adverb with simple past tense, or the when adverb with progressive aspect (see Appendix E for all passages). The second factor was whether the verb which followed the named character referred to a private mental state (implying personal knowledge) or was a communicator verb (implying public knowledge). In contrast to the previous experiments, we included no trials in which the same name was topicalized and then appeared in the sentence with the pronoun (i.e., what was called the repeated name condition). The six versions of each passage were distributed into six stimulus lists so that each rater saw 3 passages in each of the six conditions.

In addition to these 18 passages, six subordinate-clause passages were constructed, each with two versions which varied by one word, the mental state/communicator verb. Eleven filler passages were also constructed to make a total set of 35 passages.

\section{Raters and Procedure}

Raters were 40 undergraduates from Boston University who participated for course credit. Passages were presented on a computer and raters pressed a key to see each successive line. The final line included a question with response choices labeled 1-5. All lines remained in view until the rater answered the question by pressing a key. Instructions were similar to those of the previous experiments. Raters could also press a key to see the instructions summarized.

\section{Results and Discussion}

Figure 3 shows how frequently raters chose the referent that was in the same sentence as the pronoun (i.e., the intrasentential referent). Choice of the intrasentential referent was low in all the 
main-clause conditions (10\%), but was high in the subordinate-clause condition (49\%), which is the pattern found in previous experiments and consistent with all theories. This demonstrates that instructions which focus raters on the question of which character did an action can yield as strong a pattern of "blocked" coreference (i.e., strong preference for extrasentential reference) as was found in Gordon and Hendrick's (1997) study.

As expected, sentences with after conjunctions generated fewer coreference choices than sentences with when conjunctions. A surprising result was that semantic plausibility (mental state vs. communicator verb) interacted with type of sentence construction; $F(2,78)=7.5, p<0.001$. One might have expected that coreference choices would always be higher for conditions with mental state verbs, but Figure 3 shows that the mental state/communicator verb manipulation only influenced coreference in the when, simple past condition. We had assumed that use of a mental state verb would lead to

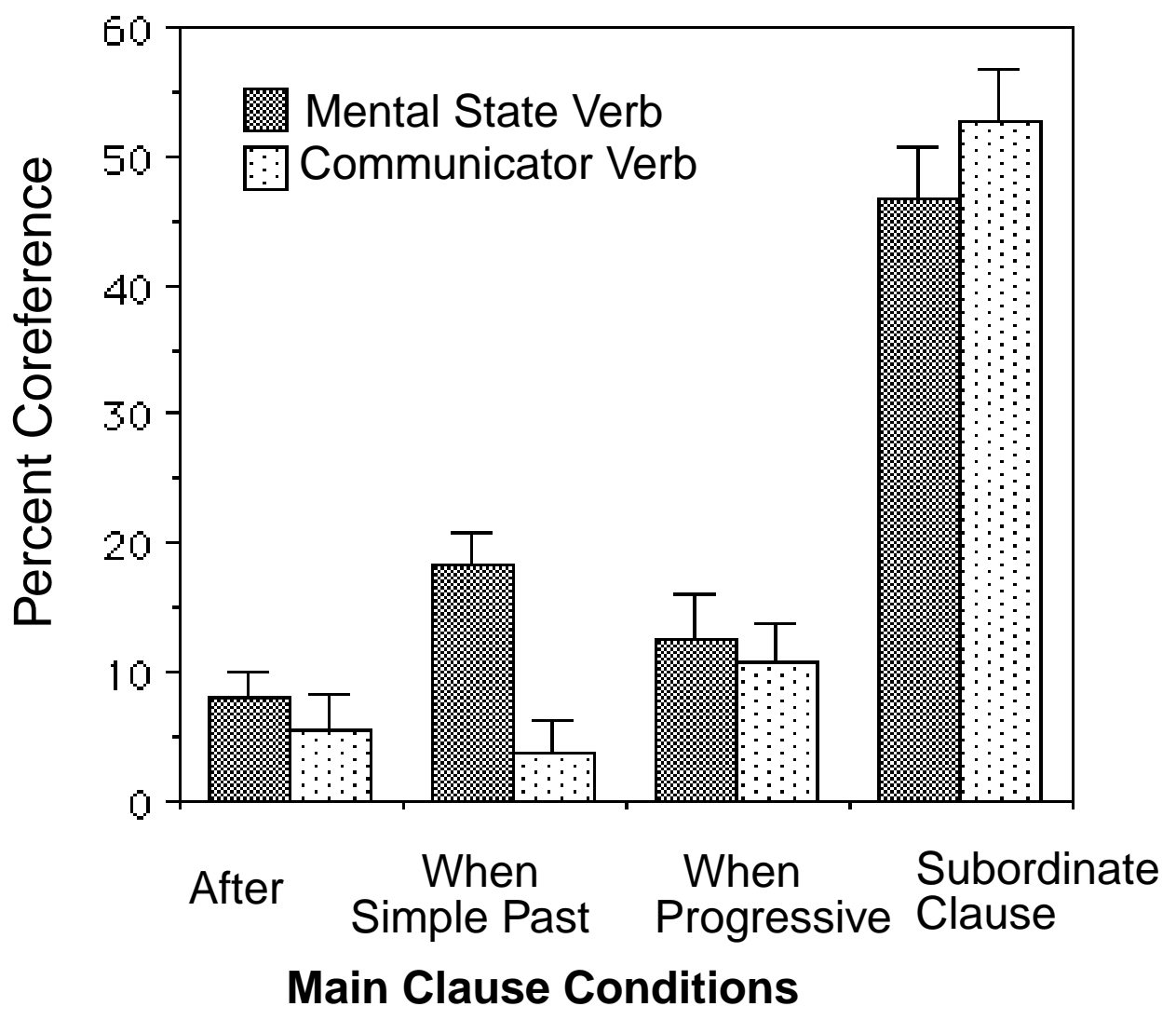

Figure 3. Percentage of intrasentential coreference judgments in Experiment 4. Error bars correspond to one standard error of the mean. 
greater coreference choices when the when construction was combined with progressive aspect as in (17a).

(17) a. She was jumping inside the car when Debra saw a large man lurking in the shadows. b. She jumped inside the car when Debra saw a large man lurking in the shadows.

Our reasoning was that progressive aspect facilitates an interpretation in which clause 1 is the setting during which the character in clause 2 has a private realization. The mental state verbs would make it most natural for the same character to be the subject of both clauses, compared to the verb of communication ("when Debra yelled at a large man..."). However, the verb manipulation had a bigger effect in the simple past tense condition (17b) than in the aspect condition. With hindsight, one can conjecture that progressive aspect by itself, with or without a mental state verb, allows some raters to accept intrasentential coreference. If progressive aspect isn't present, then the mental state verb is necessary to induce some raters to accept coreference.

The main conclusion to be drawn from this experiment is that the range of factors influencing coreference judgements includes the subordinating conjunction (when vs. after), aspect, semantic plausibility and interactions among these factors.

\section{General Discussion}

The experiments in this paper focused on sentences which begin with a pronoun and have a possible referent in a subsequent clause, because intuitions against coreference are particularly strong here. The main hypothesis investigated was that backgrounding is what allows a pronoun to precede its referent, not syntactic subordination per se. Three experiments confirmed that progressive aspect allows pronouns to refer ahead to a c-commanded referent. However, progressive aspect did not fully substitute for syntactic subordination. Sentences with progressive aspect in the first clause never allowed as much coreference as sentences with initial subordinate clauses. This suggests that, at least in English, aspect is a weaker cue to backgrounding than is syntactic subordination. It primarily facilitates judgements of coreference in two types of "conflict" situations:

- When sentences occur in isolation, people resist positing a pre-existing discourse entity (a 
referent outside the single, known sentence). Backgrounding-via-aspect helped raters obtain a coreferent interpretation in Experiment 1, which used isolated sentences.

- Given context, when there is a repeated name penalty, backgrounding-via-aspect helps raters obtain a coreferent interpretation. This was demonstrated in Experiment 2, which used sentences in context to create a repeated name penalty.

In Experiment 4, we showed that acceptance of coreference in "blocked" constructions is a result of multiple, interacting factors. Verbs which implied private mental knowledge increased acceptance of coreference for when constructions but not after constructions. This suggests that the list of factors which can override c-command includes the specific constructional semantics of when.

We've described our work as "a functionalist approach to c-command." Critics may point out that our experiments address only one syntactic contrast, that of the main/subordinate clause distinction. Ccommand is a general principle that covers many cases of allowed and prohibited coreference, including bound anaphora (i.e., the coreference distinction in Jane hates her/herself). This is true, but experimental work mandates depth of focus. The contrast between allowed coreference in "Before she sang, Susan...." and prohibited coreference in "She sang before Susan...." is particularly strong, and thus exceptions to it, as in the cases of progressive aspect, merit intensive investigation. We hope that psycholinguists will investigate functionalist alternatives to other aspects of c-command, following linguistic critiques (Huang, 1994; Kuno, 1987; van Hoek, 1997).

Critics may note that our data are fully consistent with autonomous syntax, both the older Government-Binding framework (Chomsky, 1981) and the newer minimalist perspective (Chomsky, 1995; Radford, 1997) if the when-clause is a sentential modifier, rather than a verb phrase modifier. On this view, the when clause in (18a) would not be a subordinate clause (and thus c-commanded by the main clause), but would be a coordinate clause, with a structure similar to the but construction of (18b). Theorists have long noted that coreference is possible in sentences using but and and conjunctions such as $(18 b)$.

(18) a. She was jumping into the car when Debra saw a large man lurking in the bushes.

b. He hasn't contacted me, but I'm sure John is back. (He = John; Mittwoch, 1979, cited in 


\title{
Functionalist Alternative to C-command
}

Page 28

\author{
Reinhart, 1983).
}

The two clauses of a but conjunction appear to be relatively equivalent in informational prominence. This means they can be easily diagramed at the same level of the phrase structure tree, instead of one clause being subordinate to another. Motivation for viewing sentences like (18a) as coordinate structures is that the intrasentential coreference reading is most easily attainable when there is an intonation break. This is often marked (although not obligatorily) with a comma, as in the earlier mentioned example (7), from Carden's (1982) corpus.

Functionalists would argue that equality of information prominence, combined with the meaning of but, is what allows readers to interpret the first clause in (18b) as setting or background for the second, which then facilitates a backgrounding reading and coreference. Proponents of GovernmentBinding theory (and other formalist approaches) would claim that lack of the c-command relation is what allows coreference. Are these two theoretical approaches thus notational variants of each other? One difference is that in the formalist view, there are two separate types of structures: coordinate structure having no asymmetry and thus no c-command, and main-subordinate structures with a ccommand relation. The functionalist view is that there is a cline of clause types, with clauses varying in tightness (how interdependent the meaning in the clauses is) and symmetry of information prominence (Bolinger, 1979; Foley \& van Valin, 1984).

Mandating that interpretation be dictated by the form (structure) of the phrase-structure tree should have the advantage of allowing theories to be falsified. But in cases like (18a) and (18b) interpretation appears to dictate structure. Phrase structure trees become thus a way of describing the factors which give rise to the interpretation. We have argued that informational prominence, and narrative foreground/background, is a crucial factor in determining coreference interpretations.

We believe that sycholinguistics will make its greatest headway when explanations for linguistic form are sought in the informational structure being served by these forms. Our analysis of clausal backgrounding and its relation to allowed and prohibited pronominal reference is offered as an example of this approach. 
Harris and Bates

Page 29 


\section{REFERENCES}

Ariel, M. (1990). Accessing noun-phrase antecedents. London: Routledge.

Bates, E.A., \& MacWhinney, B. (1982). Functionalist approaches to grammar. In E. Wanner \& L. Gleitman (Eds.), Language acquisition: The state of the art. Cambridge: Cambridge University Press.

Bates, E.A., \& Goodman, J.C. (1997). On the inseparability of grammar and the lexicon: Evidence from acquisition, aphasia, and real-time processing. Language and Cognitive Processes, 12, 507-584.

Berwick, R.C., \& Wexler, K. (1987). Parsing efficiency, binding, c-command and learnability. In B. Lust (Ed.), Studies in the acquisition of anaphora, volume II: Applying the constraints. Boston, MA: D. Reidel.

Bolinger, D. (1979). Pronouns in discourse. In T. Givon (Ed.), Discourse and syntax: Syntax and semantics 12. New York: Academic Press.

Bosch, P. (1983). Agreement and anaphora: A study of the role of pronouns in syntax. New York: Academic Press

Brennan, S. E. (1995). Centering attention in discourse. Language and Cognitive Processes, 10, $137-$ 167.

Carden, G. (1982). Backwards anaphora in discourse context. Journal of Linguistics, 18, 361- 387.

Carden, G. \& Dieterich, T. (1980). Introspection, observation and experiment: An example where experiment pays off. Journal of the Philosophy of Science Association, 2, 583-597.

Chafe, W. (1984). How people use adverbial clauses. Berkeley Linguistic Society, 10, 437-449.

Chomsky, N. (1981). Lectures on government and binding. Dordrecht: Foris.

Chomsky, N. (1995). The minimalist program. Cambridge, MA; MIT Press.

Crain, S. (1991). Language acquisition in the absence of experience. Behavioral and Brain Sciences, 14, 597-650.

Foley, W.A., \& van Valin, R., Jr. (1984). Functional syntax and universal grammar. Cambridge: Cambridge University Press.

Freidin, R. (1992). Foundations of generative syntax. Cambridge, MA: MIT Press.

Garnham, A. (1987). Understanding anaphora. In A. W. Ellis (Ed.). Progress in the psychology of language, Vol. 3. Hillsdale, NJ: Erlbaum.

Gerken, L., \& Bever, T. (1986). Linguistic intuitions are the result of interactions between perceptual 
processes and linguistic universals. Cognitive Science, 10, 457-476.

Gernsbacher,M.A. (1990). Language as structure building. Hillsdale: NJ: Erlbaum.

Gernsbacher, M.A., \& Shroyer, S. (1990). The cataphoric use of the indefinite this in spoken narratives. Memory and Cognition, 17, 536-540.

Givon, T. (1983). Topic continuity in discourse: A quantitative cross-linguistic study. Philadelphia, PA: John Benjamins.

Goldberg, A. (1995). Constructions: A construction grammar approach to argument structure. Chicago:University of Chicago Press.

Goodluck, H. (1981). Children's grammar of complement subject interpretation. In S. Tavakolian (Ed.), Language acquisition and linguistic theory. Cambridge, MA: MIT Press.

Gordon, P.C., Grosz, B.J, \& Gilliom, L.A. (1993). Pronouns, names and the centering of attention in discourse. Cognitive Science, 17, 311-347.

Gordon, P.C., \& Hendrick, R. (1997). Intuitive knowledge of linguistic coreference. Cognition, 62, 325370.

Gordon, P.C., \& Hendrick, R. (1998). The representation and processing of co-reference in discourse. Cognitive Science, 22, 389-424.

Harris, C.L. (1991) Alternatives to linguistic arbitrariness. Behavioral and Brain Sciences, 14, 622623.

Hopper, P.J. (1979). Aspect and foregrounding in discourse. In T. Givon, (Ed.), Discourse and syntax: Syntax and semantics vol. 12. New York: Academic Press.

Hopper, P.J. (1982). Tense-aspect: Between semantics and pragmatics. Philadelphia: John Benjamins.

Huang, Y. (1994). The syntax and pragmatics of anaphora: a study with special reference to Chinese. Cambridge: Cambridge University Press.

Kuno, S. (1987). Functional syntax: anaphora, discourse and empathy. Chicago: Chicago University Press.

Langacker, R.W. (1969). On pronominalization and the chain of command. In W. Reibel and S. Schane (Eds.), Modern studies in English. Englewood Cliffs, NJ: Prentice Hall.

Langacker, R.W. (1987). Grammatical ramifications of the setting/participant distinction. Proceedings of the Annual Meeting of the Berkeley Linguistics Society,13, 383-394. 
Lasnik, H. (1976). Remarks on coreference. Linguistic Analysis 2, 1-22.

Li, C. N. (1976). Subject and topic. Oxford: Oxford University Press.

Matthiessen, C., \& Thompson, S. (1988). The structure of discourse and 'subordination.' In J. Haiman and S. Thompson, (Eds.), Clause combining in grammar and discourse. Philadelphia: J. Benjamins.

McKee, C., Nicol, J., \& McDaniel, D. (1993). Children's application of binding during sentence processing. Language and cognitive processes, 8, 265-290;

McRae, K., Spivey-Knowlton, M.J., \& Tanenhaus, M.K. (1998). Modeling the influence of thematic fit (and other constraints). in on-line sentence comprehension. Journal of Memory and Language, 38, 283-312.

Mittwoch, A. (1979). Backward anaphora in utterances conjoined with but. Paper presented at the LSA Summer Meeting in Salzburg.

Moens, M., \& Steedman, M. (1988). Temporal ontology and temporal reference. Computational Linguistics, 14, 15-28.

Nicol, J., \& Swinney, D. (1988). The role of structure in coreference assignment during sentence comprehension. Journal of Psycholinguistic Research:.

Prince, E. (1981). Toward a taxonomy of given-new information. In P. Cole, (Ed.), Radical pragmatics. New York: Academic Press.

Prince, E. (1987). Syntax and Discourse Function. Seminar given at the 1987 Linguistic Society of America Summer Institute, Stanford University, California.

Radford, A. (1988). Transformational grammar. Cambridge: Cambridge University Press.

Radford, A. (1997). Syntactic theory and the structure of English: A minimalist approach. Cambridge: Cambridge University Press.

Rayner, K., Carlson, M., \& Frazier, L. (1993). The interaction of syntax and semantics during sentence processing: Eye movements in the analysis of semantically biased sentences. Journal of Verbal Learning and Verbal Behavior, 22, 358-374.

Reinhart, T. (1981). Definite NP anaphora and c-command domains. Linguistic Inquiry, 12, 4, 605-635.

Reinhart, T. (1983). Anaphora and semantic interpretation. London: Croom Helm.

Ritchie, G.D. (1979). Temporal clauses in English. Theoretical Linguistics, 6, 87-115. 
Rizzi, L. (1997). A parametric approach to comparative syntax: properties of the pronominal system. In L. Haegeman, (Ed.), The new comparative syntax. London: Longman.

Ross, J.R. (1969). On the cyclic nature of the English pronominalization. In W. Reibel and S. Schane (Eds.), Modern studies in English. Englewood Cliffs, NJ: Prentice Hall.

Silverstein, M. (1976). Hierarchy of features and ergativity. In R.M.W. Dixon (Ed.). Grammatical categories in Australian languages. Canberra: Australian Nest of Aboriginal Studies.

Smyth, R. (1986). Cognitive aspects of anaphora judgment and resolution. Bloomington, IN: Indiana University Linguistics Club.

Solan, L. (1981). The acquisition of structural restrictions on anaphora. In S. Tavakolian (Ed.), Language acquisition and linguistic theory. Cambridge, MA: MIT Press.

Swinney, D., \& Osterhout, L. (1990). Inference generation during auditory language comprehension. In A. Graesser and G.H. Bower (Eds.). The psychology of learning and motivation. New York: Academic Press.

Swinney, D.A. (1982). Language acquisition in the absence of experience. Behavioral and Brain Science, 14, 497-650.

Swinney, D.A. (1982). The structure and time-course of information interaction during speech comprehension: Lexical segmentation, access and interpretations. In J. Mehler, E.C.T. Walker and M.F. Garrett (Eds.), Perspectives on mental representation: Experimental and theoretical studies of cognitive processes and capacities. Hillsdale, NJ: Erlbaum.

Tanenhaus, M.K., \& Carroll, J.M. (1975). The clausal processing hierarchy... and nouniness. Papers from the parasession on functionalism. Chicago: Chicago Linguistic Society.

Thompson, S. A. (1992). On addressing functional explanations in linguistics. Language and Communication, 11, 93-96.

Trueswell, J.C., Tanenhaus, M.K., \& Kello, C. (1993). Verb-specific constraints in sentence processing: Separating effects of lexical preferences from garden-paths. Journal of Experimental Psychology: Learning, Memory and Cognition, 19, 528-553.

van Hoek, K. (1997). Anaphora and conceptual structure. Chicago, Ill.: University of Chicago Press. 


\section{Appendix A: Example passages for Experiment 1}

How the first clause appeared in the main, subordinate and aspect conditions is listed. The question that raters answered probed the identity of the person performing the action of the first clause. An additional 18 examples can be seen in the listing for Experiment 2 (Appendix B).

1. She got up from her spot on the couch when As she got ready to lie down on the couch, She was getting ready to lie down on the couch when

May heard shouting outside the house.

2. He rubbed his tired eyes in fatigue just as While he rubbed his tired eyes in fatigue, He was rubbing his tired eyes in fatigue when

Jack spotted the car behind a billboard.

3. He stopped unpacking when

After he began unpacking, He had just begun unpacking when

Jeff lost the inventory list.

4. She finished the meal preparations before Before she finished the meal preparations, She had almost finished the meal preparations when Maggie remembered they had forgotten an important ingredient.

5. He placed a few bets even though When he tried to place a few bets, He was about to place a few bets when

Mike was advised that the cops were in the bar.

6. He felt very confident until As he entered the room, He had just entered the room when Larry was accosted by a grim-faced policeman. 


\section{Appendix B: Sentences for Experiment 2}

The Experiment 2 sentences were adapted from Experiment 1 by replacing the pronoun with a name. The first six sentences appear in Appendix A.

7. Oliver discussed a bankruptcy option before After Oliver discussed a bankruptcy option, Oliver was discussing a bankruptcy option when ...Marshall hit on a solution to their problems.

8. Benny spat into the mask as As Benny spat into the mask, Benny was spitting into the mask when ...Carlos dropped the weight belts on his foot.

9. Kate began to complain about her bad grade even though While Kate began to complain about her bad grade, Kate had just begun to complain about her bad grade even though ...Liz observed that their professor was standing nearby.

10. Chris decided to purchase the magazine when When Chris decided to purchase the magazine, Chris was deciding to purchase the magazine when ...Scott saw that a friend of theirs was on the cover.

11. Timmy tossed trains at the wall when When Timmy tossed trains at the wall, Timmy was tossing trains at the wall when ...Walter discovered some trains would no longer function.

12. Dave stayed with underground writers when When Dave stayed with underground writers, Dave was staying with underground writers when ...Ben was ordered to leave the country.

13. Allen stopped to buy some extra film when When Allen stopped to buy some extra film, Allen was stopping to buy some extra film when ...Jerry saw a really cute monkey. 
14. Sherry rowed towards shore when

When Sherry rowed towards shore, Sherry was rowing towards shore when

...Felice felt the first ominous drops of rain.

15. Mark described the various expenses when

When Mark described the various expenses,

Mark was describing the various expenses when

...Bruce observed that the financial counselor looked dubious.

16. Neil started a new business when

When Neil started a new business,

Neil was starting a new business when

...Greg heard that the Feds were closing down the old company.

17. Brian decided to join the Army when

When Brian decided to join the Army,

Brian was deciding to join the Army when

...David received a telegram that their father had died.

18. Sandra yelled about the landslide when

When Sandra yelled about the landslide, Sandra was yelling about the landslide when

...Darlene was struck by a falling rock. 


\section{Appendix C: Passages for Experiment 3}

All passages are displayed in the main clause, simple past tense, repeated name version. The subordinate clause condition was created by moving the when adverb to the begining of the first clause of the final (target) sentence. The progressive aspect condition was created by introducing was before the verb of this clause, and adding -ing to the verb (progressive aspect was crossed with main/ subordinate clause type). The new name condition was created by replacing the name in sentence 2 with the second name introduced in sentence 1 . The order of the first two names in the first sentence was also varied within-item.

1. Walter and Timmy hated playing together. Walter brought out the train set. He tossed trains at the wall when Walter discovered some trains would no longer function.

2. Mary and Susan had only two days in Paris. Mary called all the tourist spots. She set the alarm for 10 a.m. when Mary learned that the museum didn't open until noon.

3. Ben and Dave were excited about being in the Soviet Union. Ben knew some Russian dissidents. He stayed with underground writers when Ben was ordered to leave the country.

4. Michelle and Tanya worked for ABC News. Michelle complained about the working conditions. She sent new material to CBS when Michelle was fired from ABC.

5. May and Pam were scared being alone in the house. May saw a human shape outside in the bushes. She hid behind the door when May saw someone trying to get in the window.

6. Rick and Jeff bid on a low-income housing project together. Rick was anxious about meeting the contractor. He drove to the office when Rick remembered they would need new blueprints.

7. Bev and Kay were co-owners of a temporary agency. Bev wanted to incorporate. She prepared the preliminary papers when Bev learned incorporating would save a lot of money.

8. Alice and Diane worked as a house-cleaning team. Alice always hated how cleaning took so long. She finished the dishes and counters when Alice noticed there was nothing left to do.

9. Bridget and Denise pooled their money to buy an evening gown. Bridget had fun wearing it to a dance. She took the dress to the dry cleaners when Bridget noticed that it was perhaps irreparably 
stained.

10. Deborah and Loraine agreed their job was the pits. Deborah thought the administration was callous. She made a snide remark about salary when Deborah saw their boss walk into the room.

11. Barbara and Margaret always made too many cookies for the bridge club. Barbara didn't want to be tempted by leftovers. She took the leftovers next door when Barbara remembered that the kids would really like them.

12. Henry and Albert both used their company's car for personal trips. Henry wondered if the company knew about this. He washed the car by hand when Henry noticed it was in bad shape from their recent camping trip.

13. Maggie and Laura grew worried because their dinner guests were late. Maggie kept the food warm as long as possible. She finished the elegant meal when Maggie learned that their guests would not be arriving.

14. Lois and Rita had the job of hiring the new typist. Lois remarked upon the dullness of the applications. She examined the applications when Lois received a phone tip about an applicant.

15. Hal and Mike were big sports gamblers. Hal suggested betting at the Red Lion. He placed a few bets when Hal was advised that the cops had just left the bar.

16. Allen and Jerry walked past the zoo's primate cages. Allen was really interested in primates. He stopped to buy some extra film when Allen saw a really cute monkey.

17. Gerald and Howard were hoping to see a bear while camping. Gerald put off cleaning up the campsite. He packed the food into the car when Gerald saw a bear prowling near by.

18. Joe and Dan went out to shovel the driveway. Joe almost slipped on the ice. He put down the shovel when Joe was knocked off his feet by a huge snowball.

19. Lucy and Susie planned to rush from the hotel to the show. Lucy wanted to pay the hotel bill soon. She unpacked the suitcase when Lucy learned the show was sold out.

20. Felice and Sherry knew the weather wasn't good for rowing. Felice watched the sky. She rowed towards shore when Felice felt the first ominous drops of rain.

21. Carlos and Benny readied themselves for the dive. Carlos checked the tank's nitrogen levels. He 
spat into the mask when Carlos dropped the weight belts on his foot.

22. William and Leonard worked on the same paramedic team. William remarked that the patient didn't look very good. He swabbed the patient's wound when William noticed it was horribly infected.

23. Scott and Chris usually bought magazines together. Scott picked up the current issue of Playboy. He wondered whether to buy the issue when Scott noticed that a friend of theirs was on the cover.

24. Louis and Ritchie knew their next door neighbor really hated noise. Louis liked to annoy the neighbor. He told a very loud joke when Louis heard their neighbor bang on the wall for silence.

25. George and Robert were nervous about the strange noises next door. George thought it was time to meet those neighbors. He walked across the lawn when George heard rattles and shrieks coming from the next house.

26. Carol and Ellen wished they had grown up playing more sports. Carol in particular hated exercising. She played golf every day when Carol learned that their grandfather had died from heart disease.

27. Greg and Neil knew their company was headed for bankruptcy. Greg felt bad about the unpaid taxes. He started a new business when Greg heard that the Feds were closing down the old company.

28. Jan and Sue worried that the firm they worked for was corrupt. Jan did appreciate the salary. She left the company when Jan saw their boss featured on America's Most Wanted.

29. David and Brian knew their father wanted a son in the service. David wondered if one must please one's parents. He decided to join the Army when David received a telegram that their father had died.

30. Peg and Eve shared an apartment in New York. Peg really liked the apartment. She stayed with relatives in Queens when Peg learned they were to be evicted.

31. Steven and Clark knew there were less violent cities to live in. Steven criticized L.A. for other reasons, too. He moved to Santa Barbara when Steven heard that a neighbor was killed by a driveby shooting.

32. Daryl and Johnny tried to earn a living scalping concert tickets. Daryl noted business was down. 
He decided to quit for good when Daryl learned of the new anti-scalping law.

33. Darlene and Sandra went for a hike on the hills over their house. Darlene remarked on the serenity of the forest. She yelled about the landslide when Darlene was struck by a falling rock.

34. Karen and Sally each wanted the other to win the dance contest. Karen vowed to at least have a good time. She danced with wild abandon when Karen was at last noticed by the judges.

35. Bob and Tim had been pool partners since high school. Bob suggested they shoot pool at school. He made a killer shot when Bob was bumped in the elbow by someone who immediately disappeared.

36. Linda and Debra walked together to the parking lot for safety. Linda wondered if car pooling might be even safer. She reached for the car door when Linda was accosted by a strange man in a black suit. 


\section{Appendix D: Passages for Experiment 4}

The three bulleted items in each passage correspond to the when simple past tense, when progressive aspect, and after simple past tense. The " "personal knowledge" and "public knowledge" verbs appear separated by the $/$.

1. Ben and Ralph were excited about being in the Soviet Union. Ralph knew some Russian dissidents.

2. He stayed secretly when Ben learned/wrote

3. He was staying secretly when Ben learned/wrote

- He stayed secretly after Ben learned/wrote ...that foreigners had to leave the country.

4. Timmy hated it when his mother made him play with Walter. Timmy brought out the train set.

5. He destroyed the trains when Walter discovered/complained

6. He was destroying the trains when Walter discovered/complained

- He destroyed the trains after Walter discovered/complained ...some trains would no longer function.

7. The zoo's primate cages were a big attraction for Allen and Jerry. Allen was really interested in primates.

8. He stopped curiously when Jerry saw/photographed

9. He was stopping curiously when Jerry saw/photographed

- He stopped curiously after Jerry saw/photographed ...a really cute monkey.

10. Denise asked Bridget if they could pool their money to buy an evening gown. Denise had fun wearing it to a dance.

11. She threw away the dress when Bridget noticed/reported

12. She was throwing away the dress when Bridget noticed/reported

- She threw away the dress after Bridget noticed/reported 
Functionalist Alternative to C-command

Page 42

...that it was irreparably stained.

13. Carlos and Benny readied themselves for the dive. Benny checked the tank's nitrogen levels.

14. He dressed quickly when Carlos realized/mumbled

15. He was dressing quickly when Carlos realized/mumbled

- He dressed quickly after Carlos realized/mumbled

...they were running behind schedule.

16. The key paramedics on the team were Leonard and William. William remarked that the patient looked bad.

17. He worked quickly when Leonard saw/said

18. He was working quickly when Leonard saw/said

- He worked quickly after Leonard saw/said

...the wound was horribly infected.

19. Scott usually liked the same type of magazines as Chris. Chris picked up an issue of Playboy.

20. He browsed curiously when Scott learned/hinted

21. He was browsing curiously when Scott learned/hinted

- He browsed curiously after Scott learned/hinted

...that a friend of theirs was on the cover.

22. Louis and Ritchie knew their next door neighbor really hated noise. Ritchie liked to annoy the neighbor.

23. He laughed cruelly when Louis heard/said

24. He was laughing cruelly when Louis heard/said

- He laughed cruelly after Louis heard/said

...their neighbor was banging on the wall.

25. Only two days were left in Mary and Susan's visit to Paris. Mary called all the tourist spots.

26. She set the alarm when Susan read/mentioned 
27. She was setting the alarm when Susan read/mentioned

- She set the alarm after Susan read/mentioned ...that the museum didn't open until noon.

28. Henry and Albert used their company's car for personal trips. Henry wondered if the company knew this.

29. He washed the car when Albert saw/complained

30. He was washing the car when Albert saw/complained

- He washed the car after Albert saw/complained ...it was in bad shape.

31. David and Brian knew their father wanted a son in the service. Brian was uncertain about his future.

32. He decided to join the Army when David learned/reported

33. He was deciding to join the Army when David learned/reported

- He decided to join the Army after David learned/reported ...their father had died.

34. Debra walked with Linda to the parking lot for safety. Linda was worried about crime.

35. She jumped inside the car when Debra saw/yelled at

36. She was jumping inside the car when Debra saw/yelled at

- She jumped inside the car after Debra saw/yelled at .... large man lurking in the shadows.

37. Steven told Clark there were less violent cities to live in. Steven criticized Los Angeles for other reasons, too.

38. He moved to Santa Barbara when Clark heard/said

39. He was moving to Santa Barbara when Clark heard/said

- He moved to Santa Barbara after Clark heard/said 
Functionalist Alternative to C-command

Page 44

...that a neighbor was killed by a drive-by shooting.

40. Jan and Sue worried that the firm they worked for was corrupt. Sue did appreciate the salary.

41. She left the company when Jan saw/reported

42. She was leaving the company when Jan saw/reported

- She left the company after Jan saw/reported

...that their boss was featured on American's Most Wanted.

43. Carol was more athletic and played more sports than Ellen, who did play some. Ellen hated exercising.

44. She played golf every day when Carol learned/pointed out

45. She was playing golf every day when Carol learned/pointed out

- She played golf every day after Carol learned/pointed out

...that both grandfathers had died from heart disease.

46. Seeing a bear was the whole point of Gerald's and Howard's camping trip. Howard knew the bears were attracted to food.

47. He inspected their store of food when Gerald saw/exclaimed

48. He was inspecting their store of food when Gerald saw/exclaimed

- He inspected their store of food after Gerald saw/exclaimed

...that a bear was prowling near by.

49. Only Greg considered Neil to be the reason their company was headed for bankruptcy. Neil felt bad about the unpaid taxes.

50. He started a new business when Greg heard/reported

51. He was starting a new business when Greg heard/reported

- He started a new business after Greg heard/reported

...the Feds were closing down the old company.

52. Daryl showed Johnny how to make money scalping concert tickets. Daryl noted business was 
down.

53. He decided to quit for good when Daryl learned of/talked about

54. He was deciding to quit for good when Daryl learned of/talked about

- He decided to quit for good after Daryl learned of/talked about ...the new anti-scalping law. 


\section{Author Notes}

Catherine L. Harris, Department of Psychology, Boston University; Elizabeth A. Bates, Departments of Psychology and Cognitive Science, University of California, San Diego. This project was supported in part by grant NIDCD R01 DC00216 to E. A. Bates. The authors thank Brian MacWhinney for helpful discussions and Alison L. Morris and Peter C. Gordon for comments on an earlier version of the manuscript. Correspondence can be addressed to Catherine L. Harris, Psychology Department, Boston University 64, Cummington St., Boston, MA 02215, USA. Email can be sent to charris@bu.edu or bates@crl.ucsd.edu. 